\title{
El Derecho Aduanero como objeto de estudio global
}

\author{
María Teresa Montalvo Romero*
}

Pardo Carrero, G., Ibáñez Marsilla, S. y Moreno Yebra F. (Dirs.) (2019-2020). Derecho Aduanero (Tomo I y II). Universidad del Rosario y Tirant lo Blanch, Bogotá Colombia, ISBN: 978-84-1336-434-6

RESUMEN: El presente texto reseña la pertinencia y originalidad de la obra "Derecho Aduanero tomo I y II" el cual contiene los temas más actuales no solo del derecho aduanero, sino de aquellas ramas jurídicas que tienen relación con el desarrollo de la actividad aduanera y del comercio exterior dentro del contexto global del siglo XXI.

Palabras claves: 1.- Derecho; 2.- Aduanas;
ABSTRACT: This text reviews the relevance abd originality of the work "Customs Law, volumen I and II" which contains the most current topics not only of customs law, but of those legal branches that are related to the development of customs activity and foreign trade within the global context of the 21st century.

Keywords: 1.- Law; 2.- Customs; 3.Legislation.

3.- Legislación.

El Derecho aduanero es una de las áreas jurídicas que más modificaciones o reformas sufre en relación con otras áreas del derecho, porque deben aplicarse actualizaciones no solo de los marcos jurídicos nacionales de cada país, sino que además, deben atenderse los principios internacionales y los acuerdos o tratados que en materia comercial firman los Estados bajo los criterios de los organismos internacionales.

La obra que se reseña es un esfuerzo de varios académicos e investigadores comprometidos con el estudio de los marcos jurídicos y de las relaciones que surgen del intercambio de mercancías entre importadores y exportadores.

El contenido del libro va más allá del Derecho aduanero, ya que la diversidad de temas que se abordan en el mismo, permite proponer una visión global de todas las aristas en las que se aplica.

La obra cuenta con la participación de cuarenta especialistas de diferentes de Instituciones de Educación Superior de México, Colombia, España, Brasil, Argentina, entre otros.

\footnotetext{
* Doctora en Derecho Público, Docente de la Facultad de Ciencias Administrativas y Sociales de la Universidad Veracruzana, Docente con perfil Prodep.
} 
El derecho aduanero es una rama del derecho público que se encarga del estudio de las funciones de la aduana, de las actividades de los importadores, exportadores y de las autoridades competentes como sujetos implicados en el desarrollo del comercio exterior, en este tenor dicha disciplina permite su estudio de manera amplia, ya sea desde el análisis del origen de esta rama jurídica hasta sus implicaciones en los procesos de integración y globalización que se viven en la actualidad.

Esta publicación, en el tomo I publicado en 2019, cuenta con tres excelentes prólogos el primero de ellos elaborado por Andrés Rohde Ponce quién es presidente de la Academia Internacional de Derecho Aduanero (International Customs Law Academy), el segundo lo realiza Ricardo Xavier Basaldúa, reconocido investigador y árbitro nacional para el Mercosur, es profesor de la Universidad de Buenos Aires de la Universidad Católica Argentina y de la Universidad Austral y el tercero está escrito por Santiago Ibáñez Marsilla, quien es miembro fundador de la Academia Internacional de Derecho Aduanero y miembro de la International Network of Customs Universities (INCU), entidad académica de referencia de la Organización Mundial de Aduanas.

El libro presenta gran seriedad académica y un rigor científico revisado por los tres directores (editores), los doctores Germán Pardo Carrero, Santiago Ibáñez Marsilla y Felipe Moreno Yebra, de la Universidad del Rosario de Bogotá Colombia; La Universidad de Valencia, España y la Universidad de Guanajuato, México, respectivamente.

Debe resaltarse que la obra no aborda necesariamente el marco jurídico de cada uno de los países de los autores, sino que se aborda el derecho aduanero, desde el punto de vista del derecho global, pero también se tocan problemáticas desde el Derecho Internacional, del derecho a la integración, del reconocimiento y garantía de los Derechos Humanos, de la economía, y por vinculación primaria desde el comercio exterior, entre otros.

El primer tomo en cuanto a su contenido se encuentra dividido en cinco partes que a continuación mencionaré:

Parte I "El derecho Aduanero", en este apartado se abordan cinco temáticas que se insertan en los antecedentes o principios generales del derecho aduanero.

La segunda parte denominada "La aduana, funciones y otros sujetos del derecho aduanero en el siglo XXI", es un apartado muy interesante por la vinculación que presenta del Derecho Aduanero con áreas como la economía digital y con la propiedad intelectual, ya que los intangibles conforman actualmente una base muy fuerte de los activos de la empresa.

En la tercera parte, "Mercancía, sistema armonizado y arancel de aduanas" se analizan temas muy concretos y específicos como la nomenclatura arancelaria y el sistema armonizado de designación y codificación de mercancías.

El ingreso y salida de mercancías (importación y exportación) se presentan en la cuarta sección y las zonas económicas especiales, los instrumentos de comercio exterior se presentan muy bien en tres capítulos dentro de la quinta parte.

En el año 2020 en el mes de enero se publica el segundo tomo de esta obra, el cual consta también de cinco apartados muy interesantes que versan sobre tópicos diferentes, teniendo así que el apartado seis relaciona muy bien el derecho aduanero con el derecho 
tributario o derecho fiscal, partiendo de la política arancelaria y del análisis de impuestos como el Impuesto al Valor agregado (IVA) en el comercio exterior.

Una de las aristas más importantes dentro de cada una de las áreas jurídicas lo conforman las medidas de defensa, de seguridad jurídica, las infracciones y los delitos, estos temas son presentados y analizados en los apartados VII, VIII y IX del tomo II, en ellos se hace alusión a figuras fundamentales como son el Antidumping, las prácticas desleales de comercio internacional, las salvaguardas, los ilícitos aduaneros y por ende también se estudian los sujetos obligados dentro del derecho aduanero.

Los últimos dos apartados del tomo II, presentan la visión regional e internacional del Derecho aduanero, así como su vinculación con los organismos internacionales. En estas secciones se analiza el desarrollo aduanal en la Unión Europea el Mercosur, entre otros y a su vez la relación con la Organización mundial del comercio y la Organización Mundial de Aduanas.

En la cuarta ola de la globalización que vivimos en este 2020, se torna indispensable el estudio del marco jurídico aduanero que regula a los entes internacionales, de las políticas públicas establecidas por los Estados en el comercio mundial, a través de la hoy denominada gobernanza global que permite la intervención de los diversos sectores gubernamentales, los organismos multilaterales internacionales y de la participación ciudadana. Esta es una obra de consulta obligada tanto para especialistas como para estudiantes de la licenciatura en Derecho y de las áreas afines como los negocios internacionales, Administración, entre otras. 